\title{
DELAYED GASTRIC EMPTYING AFTER VAGOTOMY AND DRAINAGE IN THE SPINAL CORD INJURY PATIENT
}

\author{
By Robert T. Osteen, M.D. and Ernest M. Barsamian, M.D. \\ Department of Surgery, Veterans Administration Medical Center, West Roxbury, \\ Massachusetts 02132, U.S.A.
}

\begin{abstract}
In patients with pre-existing spinal cord injuries, truncal vagotomy and drainage procedures resulted in an unacceptable incidence of prolonged gastric stasis. After gastric resection without vagotomy or closure of perforated ulcers, spinal cord injury patients resumed normal gastrointestinal function within Io days. After vagotomy, three patients were unable to eat for 25 to 57 days. A fourth patient with large gastric residual volumes died of aspiration on the $13^{\text {th }}$ day after vagotomy.
\end{abstract}

Key words: Spinal cord injury; Vagotomy; Prolonged gastric stasis.

GASTRODUODENAL ulceration associated with acute or chronic spinal cord injury is not common. In the past 24 years we have performed operations for gastroduodenal ulceration on only eight patients drawn from the population of 797 admissions to the Spinal Cord Injury Service at the Veterans Administration Medical Center, West Roxbury. Our experience with truncal vagotomy and drainage procedures in those patients has revealed enough complications to justify reporting this small collection of patients. This report presents the suggestion that vagotomy combined with the sympathetic denervation of a spinal cord injury may result in an unacceptable incidence of gastric stasis.

\section{Materials and Methods}

The records of eight spinal cord injury patients who underwent operations for ulceration of the stomach or duodenum were reviewed with respect to the indications for surgery, the operation performed, the duration of post-operative nasogastric drainage, the time from surgery to the resumption of a normal diet, and the long-term results. Two patients have been reported previously in another context (I). Eight patients underwent ten procedures for complications of gastroduodenal ulceration. Two patients had gastric outlet obstruction. There were three operations for duodenal perforation (two in the same patient). The other four operations were for persistent, active bleeding. The three perforated ulcers were oversewn initially and a delayed, definitive procedure was done on the patient whose duodenum had perforated twice. The other patient with a perforated ulcer had no definitive procedure. Of the seven definitive ulcer operations there were three vagotomy-pyloroplasties, one vagotomy-antrectomy and three subtotal gastrectomies. All four patients who had vagotomies had markedly delayed recovery of gastric function after operation.

\section{Case Summaries}

Case I. This was a 27-year-old quadraplegic male with a complete injury of the spinal cord at $\mathrm{C}_{4}-5$. Five years after his spinal cord injury he underwent truncal vagotomy and antrectomy for obstruction caused by a duodenal ulcer. Post-operatively, he 
had a large gastric residue. On the $13^{\text {th }}$ post-operative day, while still on gastrostomy drainage, he aspirated and died. A post-mortem examination showed a widely patent anastomosis and no inflammatory process in the peritoneum which might have caused an ileus.

Case 2. This is a 57-year-old paraplegic who had a complete interruption of his spinal cord of the level of T-Io. Twenty-one years after his injury a perforated duodenal ulcer was oversewn with resumption of normal gastrointestinal function by the tenth post-operative day. A second perforation occurred 9 months later while the patient was lost to follow-up. The perforation was closed and normal gastrointestinal function returned within 7 days. A pyloroplasty and truncal vagotomy was performed 6 weeks later. After that procedure he required naso-gastric suction for 20 days because of large gastric residuals and vomiting when the naso-gastric tube was clamped. An upper G.I. series on the fifteenth post-operative day showed a patent anastomosis and gastric atony. Barium could be poured passively into the duodenum by tilting the patient into a slightly prone position with the right side down. He was able to eat a normal diet by the twentyfifth post-operative day.

Case 3. This was a 47-year-old partial T-Io paraplegic who had a gastrectomy without vagotomy for bleeding 27 years after his spinal cord injury. The patient died of respiratory failure on the tenth post-operative day but his stomach was emptying satisfactorily and bowel function was normal prior to his death.

Case 4. This 23-year-old complete $\mathrm{C}_{5}-6$ quadraplegic male experienced a perforated duodenal ulcer 7 days after his spinal cord injury. The ulcer was oversewn. He could be fed by mouth on the ninth post-operative day. No definitive ulcer operation was performed.

Case 5. This 22-year-old male developed bleeding from a duodenal ulcer 6 days after an incomplete $\mathrm{C}_{5}-6$ injury. A truncal vagotomy and pyloroplasty was performed after suture-ligation of the bleeding ulcer. The naso-gastric tube was left in place for 27 days because of inadequate gastric emptying. He continued to retain large volumes of gastric contents and vomit occasionally for another month but could be fed by mouth. Two upper G.I. series showed that the pyloroplasty was widely patent but that contrast was not propelled across the vertebral column from the fundus to the antrum. Like Case 2 the barium meal could be emptied into the duodenum passively by proper positioning.

Case 6. This 22-year-old male experienced simultaneous bleeding from a posterior duodenal ulcer and perforation of an anterior duodenal ulcer 7 days after complete spinal cord injury at C-4. Vagotomy and pyloroplasty were performed. Large gastric residuals persisted and naso-gastric suction was necessary to prevent vomiting. One month after his operation an upper G.I. series showed a patent pylorus but poor peristaltic contractions and retention of contrast within the fundus. If the patient was turned prone with his left side up, the contrast could be emptied into the duodenum. Because of the positional requirement for drainage, a posterior gastroenterostomy was performed on the forty-third day after his initial operation. At the second operation the pylorus was patulous. Two weeks after the second operation ( 57 days after the first operation), he was able to eat.

Case 7. This 47-year-old man with an old, complete $\mathrm{C}_{5}-6$ injury had a subtotal gastrectomy for bleeding duodenal ulcer. Resumption of gastric function was prompt and he was able to eat within I week.

Case 8. This man was a paraplegic from an old injury at T-I2. He had a subtotal gastrectomy for duodenal ulcer with gastric outlet obstruction. In spite of pre-operative

$\mathrm{I} 9 / \mathrm{I}-\mathrm{D}$ 
dilatation of his stomach his gastric function returned to a satisfactory level by the tenth post-operative day and oral feedings resumed on the eleventh day.

\section{Discussion}

Surgery for gastroduodenal ulceration in the spinal cord injury patient is rare. Perret and Solomon (1969) reported I3 patients with gastrointestinal bleeding soon after injuries of the cervical spine. Only one of those patients had an operation. Of the 797 patients admitted to the Veterans Administration Medical Center, West Roxbury Spinal Cord Injury Service since 1953, only eight have required surgery for gastroduodenal pathology. Of those eight patients three developed ulcers within a week of the spinal cord injury. The other five patients had received their spinal injuries five to 27 years previously.

The difficulties of diagnosing abdominal pathology in a spinal cord injury patient have been emphasised by several authors (O'Hare, 1966; Charney et al., 1969; Holden, 1975). In our series, the diagnosis of obstruction and bleeding was not difficult and the three instances of perforation were treated without undue delay.

There is little information in the literature regarding the choice of operation for duodenal ulcer in the spinal cord injury patient. The only patient of Perret and Solomon (1969) who required an operation had a vagotomy and pyloroplasty. O'Hare reported that two patients from this Institution (Cases 7 and 8) were treated with subtotal gastrectomies. The report of Charney et al. (1975) includes six patients with either perforation or haemorrhage from the upper gastrointestinal tract. Their paper gives details of the diagnostic problems in those patients but does not discuss their operative management.

Our experience with vagotomy and drainage in four patients convinced us that this procedure results in an unacceptable degree of gastric stasis in the patient who also has a spinal cord injury. In all four cases there was a prolonged period before the naso-gastric tube could be removed and normal alimentation started. Two patients aspirated because of large gastric residuals and one patient required re-operation to establish better dependent drainage. Paralytic ileus was not a common effect of abdominal surgery, other than vagotomy, in the spinal cord injury patients. The recovery of gastrointestinal function followed a normal course in the three instances of perforated ulcers which were simply oversewn and the three patients who had gastrectomies without vagotomies.

The anatomy of the autonomic nervous system in spinal cord injuries is clear. The outflow of sympathetic fibres is from the dorsal and upper two lumbar segments of the spinal cord. The pyloric half of the stomach and the small intestine are supplied with motor fibres from the vagus and nerves from the sympathetic system by way of the celiac ganglion. Function of these systems following damage to one or both is complex. Experiments by Perret and Hesser in the cat showed that the maximal amplitude of contraction waves is decreased by bilateral vagotomy, especially during the early stages of distention (Perret \& Hesser, 1960). Transsection of the cervical cord in the cat resulted in a decrease in average minimal intragastric pressure without a change in the character of the stretch responses or the general pattern of gastric motility. Tracings from an intragastric balloon demonstrated that the characteristics of gastric mobility seen after vagotomy continued after cord transsection but with a flat minimal pressure base line.

The relationship between the sympathetic and parasympathetic nervous 
systems, as they effect the human gut, is not well defined. Furthermore, spinal cord injuries in humans tend to be incomplete rather than the neat transsections which can be performed easily in the laboratory. Some abnormalities of upper G.I. tract motility apparently occur after spinal cord injury but that point has not been studied carefully. One series of patients with spinal cord injuries was examined with upper gastrointestinal radiography by Pollock and Finkelman (1954). Those authors found that in about 90 per cent of the cases the barium hesitates at the fundus until the patient is placed in the prone position with the left side elevated.

Although it is impossible to draw many conclusions from a small series of patients, the consistent pattern of delayed gastric emptying in our patients with spinal cord injuries who received vagotomy and drainage procedures suggests that subtotal gastrectomy without vagotomy might be the preferred procedure.

\section{REFERENCES}

Charney, K. J., Juler, G. L. \& Comarr, A. E. (1975). General surgery problems in patients with spinal cord injuries. Arch. Surg., I10, 1083-I088.

Holden, E. M. (1966). Intestinal obstruction in spinal cord injury patients. Proc. Ann. Clin. Spinal Cord Injury Conference, 15, I IO-I I 3.

O'Hare, J. (I966). The acute abdomen in spinal cord injury patients. Proc. Ann. Clin. Spinal Cord Injury Conference, 15, I 13.

Perret, G. E. \& Hesser, F. H. (I960). Studies on gastric motility in the cat. Gastroenterol., 38, $219-230$.

Perret, G. \& Solomon, A. (1969). Gastrointestinal hemorrhage and cervical cord injuries. Proc. Ann. Clin. Spinal Cord Injury Conference, 17, 106-1 I0.

Pollock, L. J. \& Finkelman, I. (I954). The digestive apparatus in injuries to the spinal cord and cauda equina. Surg. Clin. N. Amer., 34, 259-268. 